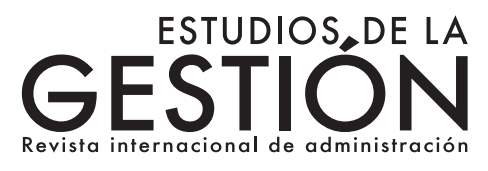

\title{
La participación como eje central del desarrollo
}

\section{Participation as the Central Axis of Development}

Participação como eixo central de desenvolvimento

\author{
Eulalia Flor \\ Universidad Andina Simón Bolívar, Sede Ecuador \\ eulalia.flor@uasb.edu.ec \\ Álvaro Sáenz \\ Universidad Andina Simón Bolívar, Sede Ecuador \\ asaenzandrade@gmail.com
}

DOI: https://doi.org/10.32719/25506641.2018.4.1

Fecha de presentación: 20 de abril de 2018 • Fecha de aceptación: 24 de agosto de 2018

Artículo de investigación

Licencia Creative Commons

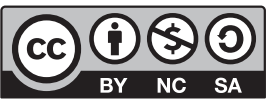




\section{Eulalia Flor y Álvaro Sáenz}

\section{Resumen}

Este artículo pretende mostrar cómo se ha ido generando un cambio histórico, no acabado, en la relación de la sociedad con el Estado, a través de la participación social en la política pública. Esto puede configurar incluso una nueva forma de hacer gobierno. Es en la experiencia latinoamericana donde se ha recreado un laboratorio en el que se gesta la oportunidad de participación. Se concluye que esta interacción es compleja y en momentos confrontativa, en la que el Estado convencional no se va a adaptar fácilmente a la presencia de grupos sociales ni estos se van a acomodar todavía a una fluida interacción con el poder establecido. Sin embargo, no cabe ninguna estrategia de desarrollo sin considerar, como elemento esencial, la participación efectiva de la sociedad.

Palabras clave: participación, sociedad, Estado, democracia, política pública.

JEL: D78 Análisis positivo de las decisiones políticas y de su ejecución.

\section{Abstract}

This article aims at showing the development of a still ongoing historical shift in the relationship between civil society and the State, through social citizen's participation in the formulation and execution of public policy, from which even a new model of governance could be yielded. Is in the Latin American experience where we can find such an experimental 'laboratory' in which opportunities of participation are constantly furnished. It is concluded that this is a complex and, in certain moments, even confrontation-laden interaction, in which the 'conventional' States cannot easily adapt and smoothly process to the constant presence of social groups and their claims, nor the latter can re-accommodate to this novel fluid interaction with established power. This presents a paradox since no strategy of development could be devised without taking as one of its essential elements, the effective participation of civil society.

Keywords: Participation, society, state, democracy, public policy.

JEL: D78 Positive analysis of the political decisions and their execution.

\section{Resumo}

Este artigo pretende mostrar como foi sendo gerada uma mudança histórica, e ainda não acabada, na relação da sociedade com o Estado, mediada pela participação social na política pública. Essa relação mediada pela participação se configura como uma possível forma de governo. No relato de uma experiência latino-americana se recria um "laboratório" onde se gesta a oportunidade concreta de participação. Se conclui que essa interação é complexa e, em alguns momentos, confrontativa, na qual o Estado convencional não se adapta facilmente à presença de grupos sociais e nem estes se acomodam a uma fluida interação com o poder estabelecido. No entanto, não se pode propor nenhuma estratégia de desenvolvimento sem considerar, como elemento essencial, a participação efetiva da sociedade.

Palavras-chave: Participação, sociedade, Estado, democracia, política pública.

JEL: D78 Análise positiva das decisões políticas e sua execução. 


\section{Contenido}

1 objetivo principal de este artículo es mostrar cómo se ha ido generando un cambio histórico, no acabado, en la relación de la sociedad con

el Estado, a través de la participación social en la política pública. Para ello se parte de un análisis sobre la participación en las nuevas democracias latinoamericanas para luego analizar algunos de los distintos mecanismos participativos instaurados en la región. Posteriormente, se explicitan los niveles o grados de la participación, según algunos autores para, por último, plantear algunas conclusiones.

\section{Introducción: la participación en nuevas democracias latinoamericanas}

Durante la década más dura de los gobiernos neoliberales, la participación y la movilización social, fueron las que generaron resistencia al modelo y lo hicieron retroceder en distintos países de América Latina, generando condiciones para su cuestionamiento. En Ecuador, en particular, la participación y movilización social de diferentes movimientos sociales liderados por el movimiento indígena generaron un ambiente simbólico necesario e instalaron en el imaginario colectivo la necesidad de cambios políticos, económicos y sociales. Como afirma Ricardo Peñafiel (2009) no se puede entender el contexto político actual de América Latina y la toma de poder de la izquierda sin tener en cuenta las movilizaciones de las décadas precedentes tales como los estallidos populares en Argentina, la guerra del gas en Bolivia, las protestas nacionales en Chile, o las movilizaciones de los forajidos en Ecuador.

A partir de la década del 80 algunos países de América Latina, con el retorno a la democracia, incorporaron espacios de participación en la vida 
pública, planteando propuestas innovadoras de cara a su vinculación con la sociedad; de esta manera buscaban otorgar (a veces solo en el discurso) un rol diverso de la ciudadanía ante sus gobernantes. Por otra parte, la ruptura con los partidos políticos tradicionales abrió la posibilidad de nuevas formas de relación entre el Estado y la sociedad, pues la mediación de estos partidos políticos perdía fuerza y legitimidad, al no haber respondido -en la prácticaa sus promesas de campaña.

En este contexto surgen varios gobiernos críticos a los postulados del neoliberalismo que buscan acercar su gestión a la población. Esta posición se consolidó en los procesos constituyentes de Venezuela, Bolivia y Ecuador donde se profundizó el debate sobre democracia y participación, así como el papel que debía jugar el Estado para fomentarla. Sin embargo, muchos de estos gobiernos han sido calificados como populistas y han llevado al espacio público su gestión cotidiana. Aun Álvaro Uribe, que no ha sido denominado por la opinión internacional como populista, llevó a la práctica los consejos comunales, que pueden ser catalogados como un medio populista de gestión del gobierno (Muñoz 2010).

Esta investigación se ha propuesto como objetivo desentrañar cómo se ha ido generando un cambio histórico, no acabado, en la relación de la sociedad con el Estado, a través de la participación social en la política pública, en situaciones reales de América Latina. Es un proceso de tal magnitud e importancia que podría configurar una nueva forma de hacer gobierno con la participación activa de actores sociales. Podemos afirmar que en algunos países de la región se ha recreado un laboratorio sociopolítico en el que se gesta la oportunidad de participación.

En condiciones en las que el Estado asume un papel más relevante que en el siglo pasado, se considera a la participación como una relación dinámica entre la sociedad y el Estado. La participación pasa, de esta manera, a ser una suerte de reconocimiento activo a las organizaciones sociales en un marco de legitimidad democrática electoral. Se incorporan nuevos componentes sociales y organizacionales como democracia participativa, comunitaria e intercultural, a la gestión pública. Como diría Boaventura de Sousa Santos:

El modelo hegemónico de democracia ha sido hostil a la participación activa de los ciudadanos en la vida política y, si la han aceptado, la han confinado a nivel local. Se trata de la conocida cuestión de escalas, en la que es posible construir complementariedades 
densas entre democracia participativa y democracia representativa y, por tanto, entre escalas locales y escalas nacionales (De Sousa Santos 2004, 8).

Uno de los retos que enfrentaron los países para retornar a la vida democrática fue el plantear modelos de desarrollo más equitativos, lo que implicaba generar mecanismos más democráticos y participativos que apunten a que las políticas públicas se orienten hacia la igualdad, redistribución y empoderamiento. A partir de lo cual se impulsó la construcción de las agendas de desarrollo local, la planificación participativa y la gestión concertada de los territorios.

De esta manera, aunque se podía aspirar a que los procesos democráticos regionales informen acerca del sujeto de la democracia (quién/quiénes), del qué (sistemas de representación y participación), del cómo (procedimientos de construcción y legitimación de decisiones, instituciones y liderazgos), también del dónde y cuándo (circunstancias geopolíticas e históricas) y del para qué (bien-estar, justicia) y para quién (universalidad) se dan los nuevos procesos democráticos (Reigadas 2011). Al analizar las experiencias particulares, resultaba evidente la coexistencia de diversas formas de conducir los procesos democráticos. En otras palabras, una mirada diferenciada a los procesos nacionales y locales dentro de cada país relativizaría esta afirmación por las innumerables (pero no generalizadas) experiencias de participación que se dan en las últimas décadas a nivel de gobiernos locales.

En cualquier circunstancia, la democracia continúa siendo una respuesta (probablemente única) para avanzar hacia una sociedad diversa más equitativa. Un aspecto clave es el nivel y tipo de participación que tenga la población y cómo esta posibilite que los gobernantes respondan efectivamente las demandas sociales, o que representen a sus electores. Lo que implica no convertir la democracia en un fin en sí mismo, sino determinar el tipo de democracia que se busca, en la línea de lo que plantea Subirats $(2011,25)$ :

Una democracia que recupere el sentido transformador, igualitario y participativo que tenía hace años. Y que, por tanto, supere esa visión utilitaria, minimalista y encubridora muchas veces de profundas desigualdades y exclusiones que tiene ahora en muchas partes del mundo. Una democracia como respuesta a los nuevos retos económicos, sociales y políticos a lo que nos enfrentamos. 
Concluyentemente que se respete la igualdad, que constituye el principio básico de la doctrina liberal; la libertad, que es la base que permite la expresión ciudadana en el Estado; y, la solidaridad, como base para privilegiar lo colectivo y el fortalecimiento del tejido social. Un sistema social que no se queda en el crecimiento económico sino que propone un tipo de vida justo y sustentable, en un marco de libertad y responsabilidad, es el ideal liberal en el que se relieva el que las personas vivan en comunidad y fortalezcan relaciones e interacciones de reciprocidad, solidaridad y fraternidad (Jara 2014).

Se plantea también dar un paso más allá respecto a esta necesaria visión liberal mediante una implantación sistemática y permanente de la participación en el quehacer estatal.

Lo que está en disputa no es solamente un conjunto más o menos innovador de políticas públicas sino también, y sobre todo, un pacto político nuevo que además contiene una dimensión de cambio civilizatorio [...]. Los cambios pueden resumirse en tres conceptos transicionales: desmercantilizar, democratizar y descolonizar [...] des-pensar la naturalización de la democracia liberal-representativa y legitimar otras formas de deliberación democrática (demodiversidad); buscar nuevas articulaciones entre la democracia representativa, democracia participativa y democracia comunitaria; y sobre todo extender los campos de deliberación democrática más allá del restringido campo político liberal... refundar los conceptos de justicia social al incluir en la igualdad y la libertad el reconocimiento de la diferencia [...], la justicia cognitiva... y la justicia histórica (De Sousa Santos 2010, 130).

De esta manera, los modelos de democracia y participación, que tradicionalmente habían sido importados de fuera desde finales de los años 80 , reciben un quiebre histórico desde los nuevos gobiernos democráticos instaurados en América Latina que fueron incorporando mecanismos novedosos.

Sería extenso pormenorizar cada uno de los múltiples mecanismos surgidos; algunos ejemplos de estas propuestas de acercamiento organizadas desde los gobiernos son: la planificación y gestión participativa local en Ecuador, los Gabinetes Itinerantes también en Ecuador, los Presupuestos Participativos en Brasil, los Centros Comunales Zonales en Uruguay, los Consejos Comunales en Venezuela y Colombia, los Comités Vecinales en México. El presente artículo se centra en los más conocidos o con mayor repercusión y que, aunque con resultados distintos, tenían en común promover la participación en sus diversas escalas. 


\section{Planificación y gestión participativa local (Ecuador)}

En Ecuador, desde la década del 80 del siglo pasado se encuentran procesos importantes, más o menos sostenidos, de planificación participativa local, destacando los procesos de Cotacahi, Guamote, Antonio Ante, Otavalo y Montúfar. Esta participación local llega a fijarse a nivel constitucional. Se manda que en todos los niveles de gobierno se conformen instancias de participación, integradas por autoridades electas y de la sociedad, para elaborar planes y políticas, vigilar derechos, elaborar presupuestos participativos y hacer rendición de cuentas y control social (Constitución del Ecuador 2008). $\mathrm{El}$ art. 100 establece los mecanismos con los que se ejercerá la participación: audiencias públicas, veedurías, asambleas, cabildos populares, consejos consultivos y observatorios.

La participación puede alcanzar niveles más altos mediante un sistema articulado y no solamente aplicando cada mecanismo participativo de manera aislada. Se trata de un conjunto de espacios en que la ciudadanía organizada se relaciona con el Estado. El Código Orgánico de Ordenamiento Territorial, Autonomías y Descentralización (2010) establece la articulación de los mecanismos de participación a través de: "Implementar un sistema de participación ciudadana para el ejercicio de los derechos y la gestión democrática de la acción municipal" (art. 53, literal d).

\section{Gabinetes Itinerantes (Ecuador)}

Se instauraron como mecanismo y espacios de trabajo a partir de 2007 en el gobierno del expresidente Rafael Correa. Esta iniciativa buscaba acercar al Estado a la comunidad con el fin de promover la credibilidad de los ciudadanos en las instituciones públicas, la articulación entre el gobierno central $\mathrm{y}$ las entidades provinciales y locales y, tener presencia en lugares alejados e históricamente olvidados. Funcionaban una vez al mes, ocasión en la cual el presidente y los ministros de Estado se trasladaban a diferentes localidades del Ecuador y, en cuatro momentos, intercambiaban con las autoridades locales y la población. 


\section{Presupuesto Participativo (Brasil)}

Fue adoptado en la ciudad de Porto Alegre en Brasil desde 1989 y es considerado como el referente participativo más innovador en América Latina. Ha sido replicado en varios países de la región y en países de Europa como España y Francia e incluso en la India. Representa la concreción de una democracia participativa redistributiva. En palabras de De Sousa Santos (2004, 20) "se fundamenta en una innovación institucional que pretendía garantizar la participación popular en la preparación y en la ejecución del presupuesto participativo municipal y, por lo tanto, en la distribución de los recursos y en la definición de las prioridades de inversión".

Asimismo constituye una herramienta de participación, gestión y control por parte de la ciudadanía que puede proponer y decidir cómo invertir parte de los recursos municipales. Su principal objetivo es contar con la participación directa de la ciudadanía en el proceso de establecer las prioridades del gasto en base a las demandas y preocupaciones de la población y plasmarlos en el presupuesto anual con un seguimiento de los resultados alcanzados.

Representan el mejor ejemplo de una ciudadanía activa que entiende que la gestión pública es algo que les compete y en la cual no solo pueden participar sino decidir.

\section{Centros Comunales Zonales (Uruguay)}

Surgen a partir de 1993, cuando se aprueba el esquema institucional vigente, en el cual se establece una subdivisión del municipio en 18 distritos en los que se instaló una agencia municipal desconcentrada o Centro Comunal Zonal con el fin de ofrecer cierta cantidad de obras y servicios. Contaban con una autoridad política local integrada con representantes políticos de los partidos y un Concejo Vecinal integrado por vecinos electos por sufragio universal a nivel de la zona, es decir, sin mediación partidaria (Portillo 2005). Estos constituyen un buen ejemplo de descentralización participativa. 


\section{Consejos Comunales (Colombia y Venezuela)}

Este mecanismo fue instaurado, con formatos y resultados diversos, en Venezuela por Hugo Chávez y en Colombia por Álvaro Uribe. En Venezuela, según lo plantea Goldfrank:

Dependiendo del lente analítico y comparativo que se use, los Consejos Comunales aparecen como la experiencia más grande e impresionante de la democracia participativa en la región o bien como un experimento más de clientelismo y, por su alcance, una amenaza para la democracia participativa (Goldfrank 2011, 42).

Los Consejos Comunales surgen con la Constitución de 1999 como entes ligados los Consejos Locales de Planificación Pública. Es a partir de 2006, en el gobierno de Hugo Chávez, cuando entra en vigencia la Ley de los Consejos Comunales que establece que tendrían una relación directa con el gobierno nacional. Se fortalecen en una dinámica mayor que las demás formas de participación política directa. Su función principal fue el impulso a la planificación, implementación y monitoreo de proyectos y programas comunitarios.

En Colombia, el presidente Álvaro Uribe instaura los denominados Consejos Comunales de Gobierno, como espacios de interacción entre el gobierno y la ciudadanía. Constituyeron espacios donde el presidente conocía y discutía, a nivel local con diversos sectores, los problemas de la ciudadanía, proveyéndole de insumos para las políticas públicas. Según la investigación de Mejía, Botero y Rodríguez $(2008,30)$ este dispositivo implicaría una relación compleja entre mecanismo de participación y populismo, tal cual lo manifiestan:

Existe una relación positiva entre la asignación del gasto en infraestructura vial y la realización de Consejos Comunales de Gobierno. Este hallazgo parece confirmar la hipótesis de la presencia de un uso populista del gasto en infraestructura vial. A través de los Consejos Comunales se asumen compromisos que implican gastos de manera que se aseguren los apoyos políticos necesarios para mantenerse en el poder. 


\section{Comités Vecinales (México)}

Fueron establecidos en 1998 con la aprobación de la segunda Ley de Participación Ciudadana del Distrito Federal (LPCDF98) en México. Se constituyeron como el nuevo modelo de participación ciudadana institucional, sustituyendo tanto a los Consejos Ciudadanos, como a la estructura vecinal (jefes de Manzana y Asociaciones de Residentes). Los Comités Vecinales eran los nuevos órganos de representación ciudadana, cuya función consistía en relacionar a los habitantes de un territorio con los organismos político-administrativos correspondientes, para supervisar, evaluar, informar y opinar sobre la gestión desarrollada.

Este mecanismo no contó con la aceptación por parte de la ciudanía, que consideró que no se le otorgaba la capacidad necesaria para incidir en la gestión, supervisión y evaluación de las autoridades delegacionales.

Todo parece indicar que la democratización del régimen del DF, el arribo de la oposición al gobierno de la ciudad, el reacomodo de las fuerzas partidarias en el panorama político de la capital, así como el "rediseño" institucional del modelo de participación ciudadana, en realidad no plantearon nuevas condiciones para el despliegue y consolidación de la misma (Espinosa 2004, 30).

Los distintos mecanismos o iniciativas de participación ciudadana que han sido descritos precedentemente reflejan la importancia que se dio en América Latina, por parte de los gobiernos democráticos, por incorporar la participación ciudadana, en asuntos del gobierno, más allá del proceso electoral.

Como lo señalan Ramírez y Welp $(2011,13)$ :

Si los procesos de democratización y descentralización abiertos desde los años ochenta en la región fueron favorables para que las dinámicas participativas adquirieran mayor vigor a nivel de los gobiernos locales, desde fines de la década de los noventa se asiste a un nuevo contexto de oportunidades políticas que ha determinado, sobre todo en los países andinos, la 'constitucionalización' de los mecanismos participativos al nivel de los Estados nacionales. Se trata de apuestas por la refundación del Estado y la democracia que han incluido a la participación directa de los ciudadanos y las organizaciones en el corazón de una definición ampliada de la soberanía popular. 


\section{Participación ciudadana}

En una perspectiva de superación de una participación convencional-electoral vinculada a la democracia de corte liberal, se enfatiza en la participación dentro de la relación sociedad-Estado, es decir a lo que Cunill (1997), denomina participación ciudadana, y que describe como aquella en la que los individuos se involucran de manera directa en acciones públicas, con una concepción amplia de lo político y una visión del espacio público como espacio ciudadano. Dejamos, así, de lado otras formas de participación señalados por la autora: a) La participación social, que se da en razón de la incorporación del individuo a asociaciones u organizaciones en pro de los intereses de sus integrantes; b) La participación comunitaria, en la que los individuos se involucran en la acción colectiva para el desarrollo de la comunidad, manteniendo una relación con un Estado benefactor y, c) La participación política mediante mecanismos de representación convencional, o sea la inclusión de los individuos en organizaciones formales y mecanismos del sistema político.

Recogemos entonces el concepto de participación como "el proceso a través del cual distintos sujetos sociales y colectivos, en función de sus respectivos intereses y de la lectura que hacen de su entorno, intervienen en la marcha de los asuntos colectivos con el fin de mantener, reformar o transformar el orden social y político" (Velásquez y González 2004, 19). En otras palabras, se concibe la participación como el proceso mediante el cual se busca promover un protagonismo soberano de la sociedad civil con miras a trasformar la sociedad actual.

Si consideramos a la participación en los procesos de construcción de políticas públicas, vemos que puede constituir un aporte crucial a la formulación, a la vez que ser una condición de posibilidad para la gobernanza democrática. Adicionalmente, entendiendo que las políticas públicas reflejan la visión del mundo que anima al Estado en un momento determinado, es decir, reflejan el proyecto político que se desarrolla desde el Estado, es importante establecer que las políticas públicas permiten a los gobiernos (de acuerdo a contextos y situaciones específicas en la cual se localizan sus intervenciones), dar respuesta a las necesidades y/o solucionar los problemas de manera eficaz y eficiente. Esto supone, además, menores niveles de burocracia y 
jerarquización y una mayor sensibilidad -por su proximidad a la poblaciónante las problemáticas a atender. Finalmente logra una innovación en las formas de ejercer el gobierno, mediante metodologías diferentes de las utilizadas habitualmente por quienes detentan poder.

Incluir y delegar a la población en el ciclo de las políticas públicas tiene una gran relevancia y conlleva beneficios sociales. Desde el lado del gobierno: dispondrían de mayor y mejor información sobre el contexto, necesidades, prioridades, capacidades y recursos de los sectores y lugares que requieran atención. La población se convierte en actor partícipe en la cogestión de servicios, obras y proyectos, los cuales responderían de mejor manera a sus necesidades locales y se optimizaría el uso de los recursos, entre otras cosas porque cuentan con mayor y mejor información, es decir, se genera una relación dialéctica en la cual las demandas sociales impulsan al Estado a la definición de políticas y acciones públicas, pero al mismo tiempo el Estado va definiendo a la sociedad con la que interactúa de acuerdo a la interrelación que promueva; lo cual constituye la base para consolidar un verdadero desarrollo.

\section{Niveles o grados de la participación}

Varios autores han buscado establecer los niveles o grados de la participación a través de las llamadas escaleras de participación. Esta figura representa ámbitos y formas de participación que logran mayor significación e incidencia en la medida en que suben de peldaño. Inician en una aportación de personas y grupos con una contribución de recursos hasta llegar a decisiones y acciones de las que son parte junto a otros o al Estado, subiendo cada peldaño en la medida en que incorporan más información, control y toma de decisiones. Los escaños se explican de abajo hacia arriba: participación con recursos, participación con trabajo, participación en la información, participación en el control y participación en la toma de decisiones. Es importante señalar que las visiones convencionales de participación se conforman con los primeros escalones e incluso los enaltecen como formas naturales de acción comunitaria. 
Una de las escaleras mejor lograda es la de Sherry Arstein (1969), quien usa esta figura para determinar los niveles desde la no participación hasta los niveles que denomina de poder ciudadano, pasando por varios peldaños desde la manipulación hasta el control ciudadano.

Figura 1

\section{Escalera de participación de Arstein}

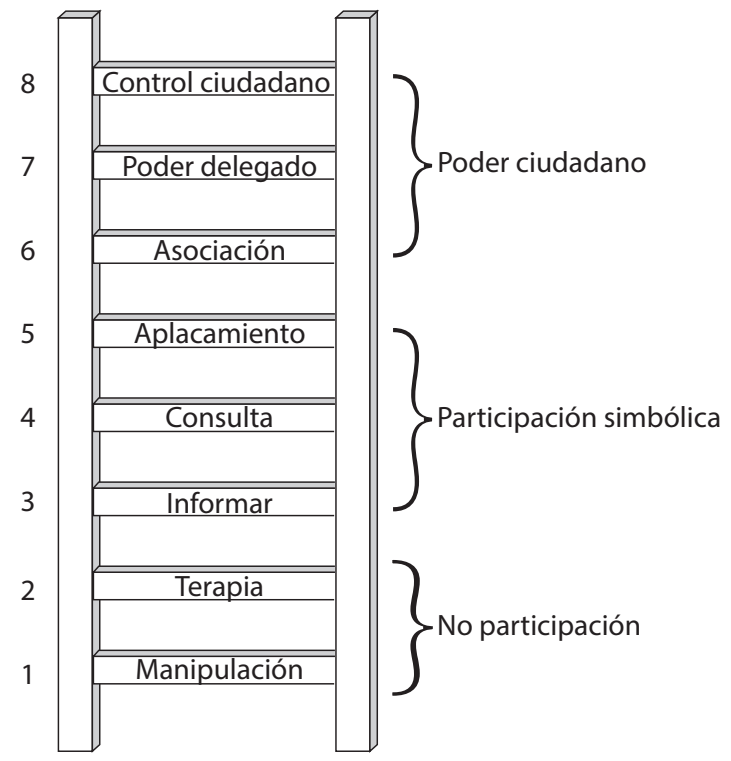

Fuente: Sherry Arstein (1969).

También está bien desarrollada la escalera de la participación de Roger Hart (2001), en la que se establecen ocho niveles de incidencia social, siendo el nivel más básico la participación manipulada, en la cual se utiliza a la población para realizar acciones que no entienden y que responden a intereses ajenos a los suyos; solo a partir del cuarto nivel, que es cuando la población dispone de información, se considera que existe participación.

Se pueden destacar tres niveles de profundidad respecto a la incidencia y calidad de la participación. En el menor, de participación básica, cada 
actor social se reúne con sus similares y reivindica los intereses propios de su grupo. Un nivel más desarrollado responde al concepto de tejido social donde se agrupan organizaciones diversas, combinan intereses y se proponen objetivos de mediano plazo. Un nivel más alto estaría dado por la articulación del grupo social con el Estado mediante medios institucionalizados de participación.

Figura 2

\section{Escalera de participación de Hart}

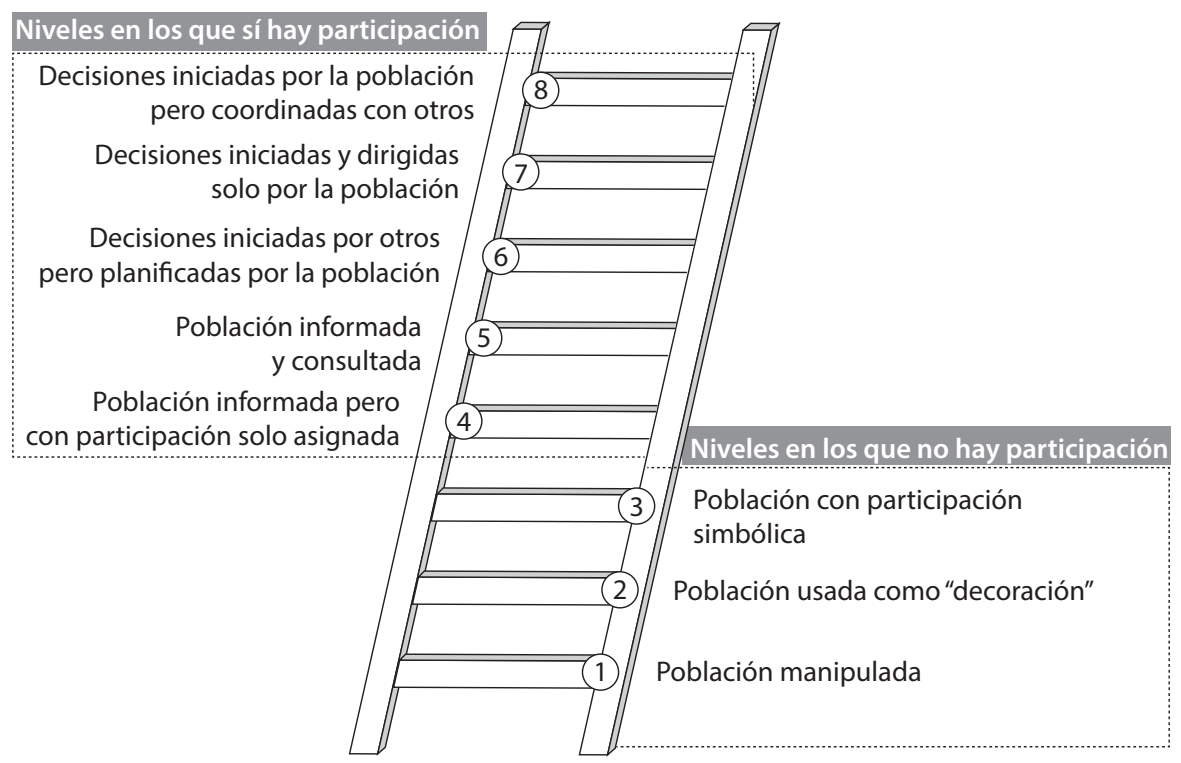

Fuente: Roger Hart (2001).

A diferencia de otras interpretaciones, el nivel más alto de participación no está en la decisión única del grupo, sino en la articulación de estas decisiones con actores externos y el Estado. Se trata de "ser tenido en cuenta en los planes de acción de los demás" (Honneth 1997, 60). La autogestión, entonces, es muy importante, pero no es el peldaño más alto de la participación cuando se habla de la sociedad en su conjunto. 
Organizar una buena participación ciudadana donde la población pueda llegar a ser influyente en las políticas públicas no es una cuestión sencilla. Abundan los manuales, la comunicación de experiencias, las evaluaciones, y existen redes, sobre todo de experiencias y gobiernos locales, para reflexionar sobre el buen hacer. No obstante, se quiere llamar la atención sobre las limitaciones que la participación halla, sin importar en el nivel en el que se encuentre, y lo que puede hacer un gobierno para eliminar esas barreras a la participación. Para ello se hace referencia a la metodología CLEAR (por su acrónimo en inglés), que proporciona una herramienta de diagnóstico para evaluar los programas de participación y cuáles deberían ser las medidas para resolver el déficit de participación (Lowndes, Lawrence y Stoker 2006). Esta metodología tiene el valor de tomar el punto de vista de la ciudadanía e incluso del ciudadano individual, y su reacción-percepción del relacionamiento logrado con el Estado. Según esta herramienta, la participación es efectiva cuando los ciudadanos:

1. Pueden participar ( $\mathrm{C}$, can do), es decir, cuentan con los conocimientos, habilidades y recursos personales y sociales para expresarse y aportar efectivamente en un proceso participativo; existen personas que no pueden, no saben cómo haberlo, no saben expresarse o no se sienten capaces de hacerlo delante de un grupo o de las autoridades y, por lo tanto, no suelen estar en esa participación. Las escuelas de ciudadanía y empoderamiento son un buen recurso para habilitar a estas personas para la participación.

2. Quieren participar (L, like to), es decir, se sienten motivados para participar, tienen sentido de comunidad, son ciudadanos interesados por la cuestión pública, por el interés público; hay personas que no sienten esto, no tienen motivación por lo público o no se mueven en el dominio del interés general. El llamado a la participación que el gobierno sepa despertar en la ciudadanía, ese interés por lo colectivo, por las políticas públicas, es condición necesaria para que funcione un espacio participativo.

3. Tienen oportunidades para participar (E, enabled to), cuando el gobierno organiza espacios de participación influyente e inclusiva, influyente para que el ciudadano considere y perciba que vale la pena participar; además es inclusiva, porque todo el mundo tendría que poder participar en una democracia. 
4. Son llamados (A, asked to), movilizados a participar ya sea por el gobierno o por grupos, redes u organizaciones públicas, privadas o voluntarias; no es suficiente con organizar espacios participativos, si las personas no se sienten invitados a los mismos.

5. Observan evidencias de que sus puntos de vista han sido tomados en cuenta, que su participación ha tenido sentido ( $\mathrm{R}$, responsed to), es decir, el gobierno tiene que practicar una devolución efectiva, explicar a los ciudadanos de qué manera su participación, sus opiniones, sus propuestas se concentraron, qué se hizo y qué no se logró realizar y explicar las razones.

Por otro lado, también merece hacer referencia a una de las propuestas más recientes y extendidas de participación, a nivel regional o nacional: la denominada Gobierno Abierto. Lanzada en 2011 como Open Government Partnership (OGP), es una iniciativa multilateral de ocho países fundadores (Brasil, Estados Unidos, Filipinas, Indonesia, México, Noruega, Reino Unido y Sudáfrica) con el propósito de proveer una plataforma internacional en la que actores locales comprometidos y representantes de sus gobiernos trabajen conjuntamente para que los gobiernos rindan cuentas, sean más abiertos y mejoren su capacidad de respuesta hacia sus ciudadanos.

La Alianza para el Gobierno Abierto ha crecido hasta contar, en la actualidad, con 64 países participantes. En todos esos países, gobierno y sociedad civil trabajan juntos para desarrollar e implementar reformas ambiciosas en torno al gobierno abierto.

Los países interesados en incorporarse a la OGP deben comprometerse a sostener los principios de un gobierno abierto y transparente y suscribir la Declaración de Gobierno Abierto (2011) cuyo objetivo principal es "fomentar una cultura de gobierno abierto que empodere y brinde resultados a los ciudadanos, y promueva los ideales del gobierno abierto y participativo del Siglo XXI". Los principales compromisos son: aumentar la disponibilidad de información sobre las actividades gubernamentales; apoyar la participación ciudadana; aplicar los más altos estándares de integridad profesional en todos nuestros gobiernos; y aumentar el acceso a las nuevas tecnologías para la rendición de cuentas.

Adicionalmente, a partir del reconocimiento del Gobierno Abierto como un proceso permanente y sostenible, se comprometen a dar el ejemplo y a 
contribuir en el avance de un gobierno abierto en otros países mediante el intercambio de mejores prácticas y experiencia y mediante la realización de los compromisos de forma voluntaria.

Esta propuesta tiene su origen en dos iniciativas que, a nivel mundial, y en un ejercicio inusual de transparencia, iniciaron el camino hacia modelos de gobierno más abiertos en los que se buscó utilizar las ventajas que ofrecen las tecnologías de información para superar el secretismo en la información pública. La primera corresponde a Estados Unidos durante la presidencia de Barack Obama, quien impulsó mediante una directiva de Gobierno Abierto la creación de un sistema de transparencia, participación pública y colaboración, con la certeza de que a través de esto se fortalecería la democracia y promovería la eficiencia y efectividad del gobierno.

La segunda responde al Reino Unido, mediante Gordon Brown y posteriormente David Cameron, quienes iniciaron, también, un proceso de apertura a través de publicar información para apoyar a los ciudadanos para que puedan comprender el funcionamiento del gobierno y el cómo se ejecutan las distintas políticas. Con esto buscaban que los ciudadanos tomen mejores decisiones y puedan dar sugerencias al gobierno.

Ambas iniciativas comparten el objetivo común de publicar los conjuntos de datos de los que dispone la administración en un ejercicio de transparencia por el que esa información vuelve a sus verdaderos dueños -la ciudadanía-, creando al mismo tiempo procesos más eficientes de funcionamiento interno y externo que mejoren las operaciones e intercambios dentro de la propia administración (De la Fuente 2012).

Es conveniente precisar que gobierno abierto no es lo mismo que gobierno electrónico, aunque a veces se usa los conceptos indistintamente. En cualquier circunstancia, se puede afirmar que se continúa evolucionando en los mecanismos que posibiliten una mejor relación entre los gobiernos y la sociedad, demandando una mayor transparencia, rendición de cuentas por parte del gobierno frente a una sociedad cada vez más informada, propositiva y exigente de que se cumplan sus demandas.

Aunque el Ecuador no se ubica como país en la Alianza para el Gobierno Abierto, algunos municipios han acogido esta filosofía de información, transparencia, participación, colaboración, innovación tecnológica y rendición de cuentas, tal es el caso del Distrito Metropolitano de Quito y el Mu- 
nicipio de la provincia del Carchi, a través del apoyo y asesoramiento de la Fundación Alternativas Latinoamericanas de Desarrollo Humano y Estudios Antropológicos (ALDHEA). Además, se considera que muchas de las leyes y procedimientos en el ámbito nacional como la Ley de Transparencia, responden a este marco propositivo.

En esta lógica y tomando como punto de partida los principios de gobernar eficaz y eficientemente, con enfoque de derechos humanos, garantizar la participación es un mecanismo que genera impactos más significativos y duraderos de las políticas públicas, "la construcción colectiva y políticamente regulada de las decisiones es lo que fortalece la democracia local y esta dinámica, es un producto en sí mismo" (Cabrero y Peña 2001, 16); es por ello, que democracia y participación van de la mano.

Es necesario considerar que la participación de la sociedad en el Estado no es un otorgamiento de los gobiernos, comúnmente llamados hacedores de la política pública; es un derecho que han adquirido los sujetos sociales y que no pasa solo por la emisión de opiniones o criterios, sino que debe ser entendida como una relación de horizontalidad y exigibilidad con los actores públicos y privados y de control de las acciones de gobierno en todos los ciclos de la política pública y de la acción gubernamental.

Una vez entendida la participación como derecho adquirido y activo, es posible reconocer que beneficia que las personas, organizaciones sociales y/o colectivos se asuman como sujetos activos en la identificación y visibilización de los conflictos y exclusiones a las que están sometidos; generen incidencia directa en las estructuras gubernamentales y en la transformación del orden social y político, y exijan de los gobiernos, en sus diversas esferas y niveles, respuestas estructuradas y prontas. Esta nueva dinámica social requiere de una difusión específica, dado que el espacio público se convierte en el sitio donde "los excluidos" pueden cuestionar explícitamente las situaciones de inequidad que sufren en la esfera privada. Habermas (1987) introduce un principio de deliberación de acuerdo al cual serían legítimas las acciones y normas que son aprobadas por todas las personas participantes en una discusión racional, lo cual resalta el carácter plural de las sociedades contemporáneas.

En concordancia con este pensamiento, nos encontramos con una propuesta de comprensión de la participación menos lineal y hasta confrontati- 
va, explicada por Fernando Tenório $(2004,2)$ como "esfuerzos articulados de actores estatales, de la sociedad civil y del capital, dispuestos a llevar adelante proyectos que surjan de negociación de intereses, inclusive divergentes y en conflicto". En este caso el poder público deja de ser un monopolio y se puede convertir en un articulador y facilitador de la participación social, con propuestas, negociación y control social; ambas partes, entonces, en calidad de agentes involucrados. Encontraríamos así un "modelo de gestión pública fundado en un proceso democrático, cooperativo y educativo, en la medida en que la población concientizada de su papel político-participativo, pasa a influenciar en todos los niveles decisorios" (Tenório 2004, 2).

Ahora bien, aunque no se puede negar que han existido avances en materia de derechos, es ineludible continuar con los esfuerzos para que se ensanchen los espacios de participación y los mecanismos para hacer efectivos estos derechos. Esto puede implicar, entre otros hechos, diseño de nuevas políticas públicas, cambios normativos y operativos sustanciales, arreglos institucionales, a través de una presión política sobre las autoridades elegidas para que representen sus intereses. En definitiva, cambios institucionales que ayuden al rescate y difusión de las buenas prácticas de atención, acompañamiento técnico de la intervención y, finalmente, la generación de espacios de interlocución para discutir y construir en conjunto las políticas públicas.

Es decir, que mientras el énfasis en la participación ciudadana desde el ángulo de lo político (democracia representativa) es el derecho ciudadano a elegir, ser elegido o deponer a sus gobernantes, desde las políticas públicas se vincula, además, al de influir en la construcción, implementación y evaluación de las estrategias de gobierno para atender las demandas sociales. Si bien existe una fuerte asociación entre democracia y bienestar público esto se debe a que un régimen democrático, se presume, debe garantizar la participación efectiva, activa y crítica de la sociedad en la construcción e implementación de las decisiones y acciones estratégicas de gobierno, ello incluye la transparencia y control del quehacer gubernamental.

Según García Linera (2011), como efecto de las recientes dinámicas de participación, y desde su experiencia, dentro del proceso de participación boliviana, se generan oposiciones que antes no existían y aparecen "nuevas contradicciones, tensiones creativas" en el gobierno abierto. Además de la oposición de los sectores sociales con los grupos de poder y agrupaciones 
políticas convencionales, aparecen cuatro nuevas contradicciones que son: entre "universalidad e intereses comunes contra intereses gremiales y locales"; entre un "Estado-monopolio" necesario para estructurar un proceso de transformación y una "sociedad creativa"; entre la necesidad de "expansión de la economía" para satisfacer las necesidades de una población con la "defensa de la madre tierra" y entre el apego al núcleo social de la revolución y la necesidad de ampliar el proceso a otras clases sociales.

Por lo precedentemente señalado, se puede afirmar que si las políticas públicas no están enmarcadas en un amplio proceso de participación, el criterio que aplican los actores públicos está sesgado y los planes y programas a implementar carecen de legitimidad efectiva; el efecto de la participación de sujetos sociales en el ciclo de políticas públicas debe estar estrechamente vinculado con el mantenimiento, reforma o transformación del orden social y político que garantice el acceso efectivo a derechos ya conseguidos y la conquista de nuevos derechos que respondan a la realidad y exigencias de dichos sujetos sociales. La participación no solo debe aumentar los canales de expresión a la sociedad civil, sino de manera fundamental favorecer su rol proactivo y crítico del quehacer gubernamental.

Por ello, la participación es crucial, no solo porque enfatiza en la exigencia al Estado para que cumpla su responsabilidad, sino que permite a los ciudadanos establecer cambios en los tejidos sociales (De Lellis 2006), superando las concepciones que concebían la participación.

Ligada, pues, a la idea general de que la ciudadanía tiene que hacerse cargo de las funciones estatales tradicionales, más que nada, en el ámbito social. Especialmente, a través de la gestión, la autogestión y la cogestión, que no son otra cosa que una adscripción, una sujeción de la participación a ámbitos administrativos y gerenciales, gracias al desempeño de un rol independiente o compartido con instancias privadas o públicas, o con el propio Estado (Flor Recalde 2009, 5).

Por lo tanto, el ciclo de la política pública está ligado de manera marcada con la participación ciudadana. Pero para que se puedan generar cambios, no solo se deben diseñar y ejecutar políticas por cumplimiento de compromisos de campaña, por coyunturas políticas, etc., sino que tendrán que irse acercando cada vez más hacia políticas públicas y por tanto hacia una "nueva concepción de la participación [...] para influir en las políticas de [...] gobier- 
nos y en las políticas gubernamentales de carácter nacional. Asimismo, [...] una apertura en los gobiernos para dialogar, ir a consensos, acuerdos" (14).

\section{Conclusiones}

En la participación se requieren actores que disputen los espacios de decisión. Esta no se activa sola, sino que requiere "una iniciativa social con fuerza política y convicción que empuje los procesos participativos" (Sáenz Andrade 2016, 220). Se trata de equipos humanos comprometidos con un proceso participativo, con decisión y conocimiento, con visión y propuestas de implementación de la participación. Puede tratarse de alianzas sociales que promueven la participación. En Ecuador existe capacidad de organización y concertación, pero en muchos casos ha prevalecido una posición más sectorialista que ha llevado a confrontaciones por encima de la búsqueda de un interés común. A su vez los sectores dominantes, que nunca fueron parte de un acuerdo por la participación, han buscado desarmar los pocos mecanismos de participación que se activaron en los últimos años.

La interacción entre el Estado y la sociedad es compleja y será en muchos momentos confrontativa. Ni el Estado convencional se va a adaptar fácilmente a la presencia de grupos sociales ni estos se van a acomodar siempre a una fluida interacción con el poder establecido. Es una relación dialéctica en la que se disputan entre una participación conducida, articulada y casi cooptada desde el Estado y la participación de la sociedad que irrumpe, cuestiona y disputa el espacio de poder.

Es importante concluir en que la combinación de mecanismos electorales de decisión con formas de participación, si bien no se aplican de manera sistémica, permite que la democracia electoral se revalorice con la compañía de otras formas de participación, pues la presencia social no queda en abandono luego de la elección y, además, por vía electoral se accede a decisiones normativas, territoriales y de revocatorias de mandato.

Asimismo, la existencia de formas y mecanismos de participación abre paso a nuevas situaciones y contradicciones en la sociedad, las que recién se están avizorando. Por último, cualquier estrategia de desarrollo debe incluir, necesariamente, como elemento esencial la participación efectiva de la sociedad. 


\section{Referencias}

Arnstein, Sherry R. 1969. "A Ladder of Citizen Participation". Journal of the American Institute of Planners 25, No. 4: 216-224.

Cabrero, Enrique, y José Peña. 2001. Instrumentos del new public management para construir una new public governance. Washington D. C.: INDES / BID.

Cunill, Nuria. 1997. Repensando lo público a través de la sociedad. Caracas: CLAD.

De la Fuente, Carlos. 2012. "Gobierno como plataforma: retos y oportunidades. El desafío hacia el gobierno abierto en la hora de la igualdad”. En Gastón Cocha y Alejandra Naser, edits., El desafio hacia el gobierno abierto en la hora de la igualdad, 65-86. Santiago: CEPAL.

De Lellis, Martin. 2006. Psicología y políticas públicas de Salud. Buenos Aires: Paidós.

De Sousa Santos, Boaventura. 2004. Democratizar la democracia: los caminos de la democracia participativa. Ciudad de México: Fondo de Cultura Económica.

---. 2010. Refundación del Estado en América Latina. Lima: Instituto Internacional de Derecho y Sociedad.

Ecuador. 2008. Constitución de la República del Ecuador.

---.2010. Código Orgánico de Ordenamiento Territorial, Autonomías y Descentralización. Quito: Asamblea Nacional.

Espinosa, Mario. 2004. Historia y cultura politica de la participación ciudadana en la ciudad de México. Ciudad de México: UACM.

Flor Recalde, Eulalia. 2009. La participación ciudadana en la vigilancia de la gestión pública por resultados. Salvador de Bahía: CLAD.

---. 2017. "Participación, democracia y espacio público". Tesis doctoral en Ciencia Política y Administración. Universidad del País Vasco, Leioa.

García Linera, Álvaro. 2011. "Estado, revolución y construcción de hegemonía”. Video de Youtube, a partir del Foro Internacional de Filosofía relizado en Maracaibo. 〈https://www. youtube.com/watch?v=K9sUyrQi3p0». Consulta: marzo de 2018.

Goldfrank, Benjamín. 2011. Los consejos comunales: ¿avance o retroceso para la democracia venezolana? Quito: FLACSO.

Habermas, Jürgen. 1987. Teoría de la acción comunicativa. Madrid: Taurus.

Hart, Roger A. 2001. La participación de los niños en el desarrollo sostenible. Barcelona: UNICEF.

Honneth, Axel. 1997. La lucha por el reconocimiento. Barcelona: Crítica Grijalbo Mondadori.

Jara, Carlos. 2014. Desplegando el Buen Vivir: el papel de las redes y las comunicaciones. Quito: ENIEP / SENPLADES.

Lowndes, Vivien, Pratchett Lawrence y Gerry Stoker. 2006. Diagnosing and Remedyng the Failings of Official Participation Schemes: The Clear Framework. Cambridge: Cambridge University. 
Mejía, Luis Bernardo, Felipe Botero y Juan Carlos Rodríguez. 2008. ¿Pavimentando con votos? Bogotá: Colombia Internacional.

Muñoz, Janeth Patricia. 2010. "Gabinetes itinerantes, enlaces ciudadanos y consejos comunales”. Ecuador Debate, No. 80: 155-178.

Open Government Partnership. 2011. Declaración de Gobierno Abierto. Consulta: febrero de 2017. 〈https://www.opengovpartnership.org/declaraci-n-de-gobierno-abierto〉.

Peñafiel, Ricardo. 2009. "Discours et subjectivation. Soulèvements populaires et ouverture de nouveaux espaces politiques". En Natacha Borgeaud y otros, edits., Penser le politique en Amérique Latine. La recréation des espaces et des formes politiques, 197-213. París: Khartala.

Portillo, Maricela. 2005. Culturas juveniles y cultura política. Barcelona: Universidad Autónoma de Barcelona.

Ramírez, Franklin, y Yanina Welp. 2011. "Presentación del dossier: nuevas instituciones participativas y democráticas en América Latina". Íconos, No. 40: 11-20.

Reigadas, María Cristina. 2011. "Debates actuales sobre democracia en América Latina". Revista de estudos antiutilitaristas e poscoloniais 1, No. 2: 166-187.

Sáenz Andrade, Álvaro. 2016. "La participación social en la relación sociedad-Estado contemporánea". Tesis doctoral en Administración. Universidad Andina Simón Bolívar, Sede Ecuador, Quito.

Subirats, Joan. 2011. Otra sociedad, ¿otra política? Barcelona: Icaria / Asaco.

Tenório, Fernando Guilherme. 2004. Cidadania e desenvolvimento local: casos brasileiros. Madrid: CLAD.

Velásquez, Fabio, y Esperanza González. 2004. "La planeación participativa en Bogotá D. C. análisis y propuestas". Documento de trabajo. Consulta: enero de 2004. «http://www.funda cióncorona.org.co/descargas/planeación\%20participativa\%20en\%20Bogotá.pdf . 